\title{
Introduction: exclusion and inclusion - the role of IP laws in a shared knowledge environment
}

\section{Dana Beldiman}

\section{FROM INNOVATION TO COLLABORATION}

The past few decades have brought profound changes to all aspects of the innovation process. In the past, scientific and technological research and development (R\&D) was mainly performed within manufacturing industries, usually as part of vertically integrated $\mathrm{R} \& \mathrm{D}$ and product innovation processes. Knowledge was generally produced in-house and maintained in a closed, internally proprietary, and localized environment, within large enterprises, universities, or think tanks. ${ }^{1}$

This paradigm began to change as the pace of technological development accelerated and technologies became more complex and fragmented. Difficulties in covering all stages of the innovation and production process internally led firms to seek complementary expertise and disciplines from outside their immediate chain of production and supply. ${ }^{2}$ Research tools became more specialized and their cost decreased. This allowed new and, in many cases, small- and medium-sized enterprises to enter the R\&D field and caused the number of players and overall participation in the innovation process to increase.

1 WIPO Intellectual Property Report 2011, ch. 1, section 1.2, p. 23, available at www.wipo.int/export/sites/www/freepublications/en/intproperty/ 944/wipo_pub_944_2011.pdf.

2 See Gustavo Ghidini and Andrea Stazi, Chapter 1. 
One of the cornerstones of the open innovation ${ }^{3}$ environment is the ability to make free and massive use of Internet-based communication platforms. This ability, which is largely taken for granted, is the result of key policy decisions made in the early days of the Internet to shield providers of information society services from infringement liability. ${ }^{4}$ This model, which was adopted by legislators on both sides of the Atlantic 5 and spread to other geographic areas as well, has allowed society to take full advantage of the opportunities created by networked technologies and the communication facilities they provide. ${ }^{6}$ Upon this foundation, numerous successful innovative services have been built, which provide the technological basis for the functioning of the open innovation paradigm. ${ }^{7}$ The unrestricted emergence of new communication platforms thus enabled the interaction with new players, which previously had been beyond a firm's traditional supply and production environment and its localized geographic boundaries. Fuelled by these developments, open innovation emerged as an environment in which knowledge-based industries tend to abandon the vertical integration model in favor of a horizontal one and to rely on knowledge and skills from outside sources to complement their own internal resources. ${ }^{8}$

3 The term 'open innovation' generally refers to models of collaborative knowledge generation, largely enabled by new technology platforms which allow access to information from and collaboration with a wide circle of participants, including competitors, universities, customers, consumers, and so on. This should not be confused with the concept of 'open source', a movement prevalent primarily in the field of software development, which promotes an ethos of free sharing.

4 See Michael W. Carroll, Chapter 8, for a description of the evolution of this policy.

5 DMCA, 17 USC s. 512(a); Directive 2000/31/EC of the European Parliament and of the Council of 8 June 2000 on certain legal aspects of Information Society services, in particular electronic commerce, in the Internal Market ('Directive on Electronic Commerce') [2000] OJ L178/14.

6 See generally, D. Beldiman, 'Introduction' in D. Beldiman (ed.), Access to Information and Knowledge: 21st Century Challenges in Intellectual Property and Knowledge Governance (Cheltenham (UK)/Northampton, MA, Edward Elgar, 2013).

7 See Michael W. Carroll, Chapter 8.

8 Open innovation has been defined as 'the use of purposive inflows and outflows of knowledge to accelerate internal innovation and to expand the 
This new paradigm requires a new type of interaction among the participants in the innovation process. Traditional rigid organizational structures are abandoned and dividing lines between firms' functions become more fluid. Close collaboration in innovation and production generates a variety of new relationships among firms, ranging from simple contract $\mathrm{R} \& \mathrm{D}$, licensing in and out, to acquisition or dissemination of new technologies, cooperative $\mathrm{R} \& \mathrm{D}$, cross licenses and collective $\mathrm{R} \& \mathrm{D}$ by industry associations or government supported institutions. ${ }^{9}$ Openness accelerates innovation ${ }^{10}$ and spawns new fields of research and new industries and endeavors, of increased complexity, often cross-disciplinary in such diverse fields as synthetic biology, ${ }^{11}$ information technology, ${ }^{12}$ creative industries, ${ }^{13}$ and others.

In short, open innovation enables new paths for creation and dissemination of knowledge, more players in the market and new forms of relationships. It gives rise to a paradigm in which competitive advantage no longer necessarily rests on exclusive knowledge, instead primarily on the ability to access the right kind of knowledge at the right time.

These developments require a rethinking of the role that intellectual property (IP) laws should play in order to meet the needs of open innovation effectively. The individual chapters of this book will highlight developments in various areas of IP law, prompted by the realities of an open and shared knowledge environment.

markets for external innovation, respectively': WIPO Intellectual Property Report 2011, p. 47, quoting Henry Chesbrough, 'Open Innovation: A New Paradigm for Understanding Industrial Innovation' in Henry Chesbrough, Wim Vanhaverbeke and Joel West (eds), Open Innovation: Researching a New Paradigm (Oxford University Press, 2006); Gustavo Ghidini and Andrea Stazi, Chapter 1.

9 Other forms of collaboration include R\&D consortia, ventures coproduction, comarketing, coauthorship with universities, research organizations, and so on: WIPO Intellectual Property Report 2011, ch. 1.

$10 \quad$ Ibid. p. 47.

11 See Timo Minssen and Jakob B. Wested, Chapter 3.

12 Michael W. Carroll, Chapter 8.

13 See Dana Beldiman, Chapter 6. 


\section{EXCLUSION AND INCLUSION: THE ROLE OF IP IN A SHARED KNOWLEDGE ENVIRONMENT}

IP laws grant exclusive rights to inventors so that they can position their inventions in the market advantageously. Yet in an open innovation environment, competitive advantage tends to reside less and less in the exclusive right to knowledge. How is this apparent conflict to be reconciled?

Neoclassical economic theory teaches that the exclusionary nature of IP laws is dictated by the need to avoid a market failure that would cause undersupply of knowledge products. ${ }^{14}$ IP laws provide inventors with a temporary competition-free environment to allow them to derive economic gain from their invention. ${ }^{15}$

Open innovation does not detract from the ability for economic gain. Instead, open innovation relates to the proper allocation of IP resources among players in the economy and creates an environment which facilitates reallocation. A system based on private arrangements for allocation of IP rights leads to greater efficiency in the use of knowledge and thus furthers innovation.

For policy-makers it is notoriously difficult to determine the proper quantum of exclusivity that should granted by any particular IP right. The law therefore approximates the quantum of exclusivity based on a variety of economic assumptions. Individual IP owners, on the other hand, have the advantage of knowing the specific circumstances in which an IP asset is used. They are in a position to assess, with greater accuracy, the point at which ownership and exploitation of a particular IP asset is no longer of value, or is of greater value when traded for other benefits. Once that point is reached, a rational IP owner can relinquish exclusivity in exchange for a benefit, and at the same time, free the asset up for use by third parties. ${ }^{16}$

14 See generally, W. Landes and R. Posner, The Economic Structure of Intellectual Property Law (Cambridge, MA, Harvard University Press, 2003).

15 See ibid.

16 From a public policy perspective, it should be noted that a certain amount of sharing/access is considered to be in the interests of public welfare, by making valuable intellectual achievements available to the common benefit. 
The option to relinquish IP rights is based on the fact that the law provides for, but does not mandate, the right to exclude. In other words, the right to include remains in the owner's discretion. Once considered from the perspective of inclusion and relinquishment of exclusivity, it becomes clear that, given their non-rivalrous nature, IP assets are particularly suitable for shared use, as they enable an asset's simultaneous use by multiple parties, without the risk of depletion. The interplay between the right to exclude and the right to include forms the theoretical basis for creating a privately ordered knowledge environment.

Many different paths lead to the shared use of knowledge. One of the more prevalent mechanisms is the use of contractual relations as a vehicle for transferring knowledge, operating against the background of IP laws. ${ }^{17}$ Contract law and IP law serve as its primary legal instruments.

Contract law doctrines enable the structuring of malleable relationships between parties in knowledge transfer agreements. They establish the parties' rights and obligations vis-à-vis each other, including the terms of use, exploitation and transfer of IP assets. While contract law allows a great deal of flexibility in the allocation of IP rights, this flexibility brings with it certain risks due to the non-rivalrous nature of information. Open innovation involves a multitude of relationships among different players, seeking to share in the most recent inventions and know-how. Use of IP assets among multiple players gives rise to the risk of IP interdependence, in other words, the possibility of inconsistent contractual rights over IP assets, arising in the course of relationships such as outsourcing of R\&D, joint ventures, licensing, sublicensing, and so on. ${ }^{18}$

Turning to IP laws, it becomes apparent that they play a dual role. First, by virtue of their erga omnes ${ }^{19}$ effect, IP doctrines transform knowledge from a public into a privately appropriable,

\footnotetext{
17 Gustavo Ghidini and Andrea Stazi, Chapter 1.

18 The concerns arising out of this situation are discussed by Jacques de Werra, Chapter 5.

19 Entitlement enforceable against all third parties, in contrast with the right to enforce only against contracting parties, conferred by contractual relationships.
} 
merchandisable asset, ${ }^{20}$ defining and delimiting the scope of rights and making them defensible vis-à-vis third parties. Second, by virtue of the ability to exercise exclusivity selectively, IP laws enable parties to structure arrangements that meet their respective economic goals, in terms of use, exploitation, geographic scope, subject matter scope, assignability, and so on. In particular, in the context of open innovation, their role is to enable collaboration between different players, by channeling knowledge among them in accordance with the structure and rules of the respective collaborative venture. ${ }^{21}$

These doctrines form the core theoretical legal framework that underlies the business relations and knowledge transfer agreements in an open innovation environment. The following discussion illustrates some of the issues raised by the interplay of contractual and IP norms in the context of shared use of IP assets.

\section{INTERSECTION OF STANDARDS, FRAND AND COMPETITION LAW}

Standardization of technologies poses one of the most significant challenges to IP laws, in particular to patent law. Standards require shared use of technologies in order to ensure interoperability and to allow establishment of common platforms in the context of complex technologies. Technology standards are mostly used by competitors, each seeking to secure a share of the product market for the respective technology. Thus, in addition to complex IP and contract issues, standardization may raise antitrust/competition problems as well, although, absent a dominant market position by the patent holder, in most instances no such issues are present. ${ }^{22}$

20 See H. Ullrich and A. Heinemann in U. Immenga and E.J. Mestmäcker (eds.), Wettbewerbsrecht, vol. 1, EU Part 2, 5th edn (Munich, C.H. Beck, 2012), p. 1986 et seq. (GRUR B. annot. 22) with references.

21 This includes rules on contribution of capital and/or capacities, on the division and/or centralization of work and on the distribution of results, including the 'rights' of exploitation, see ibid.

22 Standards may be created by regulation, institutions or standard setting organizations which operate on a national, regional or international basis and may be found in all types of industries and businesses from railroads to business conduct, Timo Minssen and Jakob B. Wested, Chapter 3. 
However, patents that are essential to a particular technology (standard essential patents or SEPs) ${ }^{23}$ may raise serious antitrust/ competition concerns, as such patents confer on their owner the ability to restrict competing innovation in the licensing market, as well as downstream markets. In recognition of this fact, competition laws and standard setting organizations (SSOs) impose on licensors of SEPs the obligation to deal with license seekers on terms that are 'fair, reasonable, and non-discriminatory' (FRAND). ${ }^{24}$ SSOs generally include FRAND commitments in their license agreements, thereby subjecting owners of declared SEPs to such commitments.

Issues surrounding SEPs and FRAND terms have presented challenges to courts for a number of years and are far from being resolved. One of the thornier issues facing courts and competition authorities is whether a SEP holder who is subject to a FRAND commitment has the right to enjoin an implementer (license seeker) from use of the SEP. ${ }^{25}$

In general, under most countries' patent laws, the grant of injunctions does not give rise to antitrust implications. In the case of SEPs, however, competition authorities are concerned that injunctions may have adverse competitive effects, leading to the distortion of licensing negotiations and to competition-restrictive licensing terms, and ultimately have a negative impact on consumer choice and prices. ${ }^{26}$ Particularly in industries where time is of the essence, such as tablet computers and mobile phones, the delay caused by an injunction could be tantamount to precluding the

23 A 'standard essential patent' (SEP) is a patent that is essential to the implementation of a particular standard and which cannot be designed around. European Commission, Google/MMI, COMP/M.6381.

24 See EC proceeding against Qualcomm for excessive pricing, concluded without resolution, available at http://europa.eu/rapid/press-release_MEMO-09516_en.htm?locale=en.

25 Under European law, SEP owners are generally held to occupy a dominant position in the licensing and downstream market of the respective technology, and therefore to be subject to competition law.

26 European Commission, Motorola Mobility and Samsung Electronics: Frequently Asked Questions, 29 April 2014, available at europa.eu/rapid/pressrelease_MEMO-14-322_en.pdf; see also European Commission antitrust proceeding in the Apple Samsung case, available at http://europa.eu/rapid/pressrelease_IP-13-971_en.htm. The European Commission takes the position that when seeking injunctions in the context of SEPs, the hold-up exists regardless of whether the effects are likely or actual. 
license seeker from entering the market. In such cases, the mere seeking of injunctions may 'hold up' implementers of the particular technology and be sufficiently threatening to implementers to cause them to pay royalties in excess of FRAND rates, to relinquish certain rights, such as the right to challenge the validity of the SEP, or to agree to terms that they otherwise might not have agreed to. EU law views this an abuse of a SEP holder's dominant position. ${ }^{27}$ Chapter 2 provides an in-depth discussion of the risks of the hold-up effect. 28

Some initial guidance on the issue of injunctions in a SEP setting was provided by a German court. The Orange Book case held that the implementer of a SEP can successfully defend against an injunction sought by a SEP holder if (a) the implementer makes an unconditional offer to conclude a license agreement, (b) refusal of which by the SEP holder would be unfair or discriminatory, and (c) the implementer fulfills its contractual obligations by, for instance, paying or depositing appropriate royalties..$^{29}$ This standard was, however, viewed with skepticism by the European Commission. The concern voiced was that requiring the implementer to make an 'unconditional offer' would unreasonably strengthen a SEP holder's negotiation position and would risk forcing implementers into restrictive license agreements. In other words, the hold-up risk would remain present. ${ }^{30}$ Thus the Orange Book rule might easily lead to the worst overall outcome, namely that an implementer would be precluded from use of a technology, despite its willingness to take a license.

27 TFEU Art. 102 prohibits the abusive exploitation of the dominant market position by an undertaking. The holder of a SEP occupies a dominant market position under antitrust law in both the license market and the downstream market, see European Commission, IP/13/406 06/05/2013, available at http://europa.eu/rapid/press-release_IP-13-406_en.htm.

28 See Thomas Vinje, Chapter 2.

29 German Federal Court of Justice, Orange Book Standard Decision, KZR 39/06 (2009).

30 '[T]he worst-case scenario [namely that] a company willing to take a license for standard-essential patents on FRAND terms is hit by an injunction' (emphasis added): J. Almunia, Vice President of the European Commission responsible for Competition Policy, EC Press Release, 20 September 2012, available at http://europa.eu/rapid/press-release_SPEECH-12-629_en.htm. 
Under a more balanced standard, the implementer should merely have to demonstrate willingness to enter an agreement. This requirement would pose less danger to competition than an 'unconditional offer', in that it would eliminate the hold-up risk. Implementers who demonstrate a willingness to submit to the licensing framework provided for by the FRAND commitments could thus benefit from a safe harbor protecting them against injunctions sought by SEP owners. ${ }^{31}$ This solution would balance 'the interests of SEP holders to be appropriately remunerated for their IP and the interests of implementers of standards to get access to standardised technology on FRAND terms'. ${ }^{32}$

This solution is not entirely devoid of risk. 'Willingness to negotiate' is a vague and unreliable standard. One can envision the reverse risk - that of a hold-out - where an implementer engages in lengthy non-committal negotiations without being subject to firm obligations. Meanwhile, the SEP holder would have to tolerate the unlawful use of its patent for an unforeseeable time, its remedy being limited to damages in a remote future. ${ }^{33}$

The issue of SEP injunctions in a FRAND context provides a good illustration of how proper interpretation of a specific IP law can facilitate shared use of an IP asset and can channel its use to the parties who are in a position to make beneficial use out of it. In the policy space between the extremes of (a) prohibiting use by the implementer and (b) allowing the implementer's use without adequate compensation to the SEP owner, one of the standards discussed above ${ }^{34}$ or a modified version thereof, is likely to reach a balance point that places the parties into reasonably equal negotiating positions so that a deal can be reached. It is up to courts and SSOs to work out where that point lies, taking yet another step

31 European Commission, Motorola Mobility and Samsung Electronics: Frequently Asked Questions, n. 26 above.

32 Ibid.

33 Huawei v. ZTE, Case no. 4b O 104/12, District Court Dusseldorf, Germany, 21 March 2013, referral to the Court of Justice of the European Union (CJEU) for clarification of the proper standard for evaluating injunctions involving SEPs subject to a FRAND commitment.

34 Orange Book 'unconditional offer' and the 'willingness to negotiate' standard in defending against injunctions relating to a FRAND encumbered SEP. 
toward facilitating the smooth flow of information required for an open innovation environment. ${ }^{35}$

An effective and comprehensive resolution of licensing in the FRAND context and the right to injunctions is also crucial for newly emerging fields of expertise, such as synthetic biology, discussed in detail in Chapter 3, whose overall IP treatment is still under debate. Synthetic biology is the field that deals with design and construction of new biological parts, devices and systems, and the re-design of existing natural biological systems. ${ }^{36}$ It illustrates the questions arising in a new and promising, but legally largely uncharted field, in which the approach to innovation is yet to be defined. Some stakeholders view open innovation as a necessity to tackle innovation gaps, while others view it as an opportunity of 'free sharing' that would allow them to challenge traditional IP rights-based innovation models. Standardization is, of course, key to developing an IP model that allows synthetic biology as a field of research to move forward on solid bases. While efforts have been made in this regard, they are in an incipient phase. Much work is required to help synthetic biology reach its expressed goal of effective translational exploitation, in an open, standardized, and safe innovation system. Given the immense security risks of this new technology, effective legal strategies and regulations are critical for both the industry and society.

\section{TRADEMARK LAW AND THE CONCEPT OF 'OPENNESS'}

Trademark law issues may arise out of shared use as well, albeit of a slightly different nature. Unlike patents and copyright, trademarks are not assets in the nature of public goods ${ }^{37}$ and therefore are not characterized by non-rivalry and non-excludability. The incentive and exclusivity rationale present in patent and copyright doctrine therefore does not apply. Yet, trademark law requires a different, and perhaps more stringent sort of exclusivity. Trademarks are unique indicators of commercial source, in that a trademark is

\footnotetext{
35 Thomas Vinje, Chapter 2.

36 Timo Minssen and Jakob B. Wested, Chapter 3.

37 Landes and Posner, n. 14 above.
} 
capable of designating only one single source without giving rise to likelihood of confusion. Third party use would inevitably undermine the mark's uniqueness and prevent it from fulfilling its purpose. ${ }^{38}$ Possibly, because of the apparent obviousness of this conclusion, the question of shared use of trademarks has received little attention.

Still, as pointed out in Chapter 4, in the trademark area private ordering resulting in shared use of trademarks tends to occur with increasing frequency. Such use takes the form of delimitation agreements, which demarcate the parties' mutual areas of exclusivity, by limiting the use of respective signs to particular product sectors, geographic areas, target groups, get-ups, and so on. Given their flexibility in the face of changing business relations, such private coexistence agreements fulfill an important business need.

To what extent such agreements are objectionable from the perspective of trademark policy remains to be determined. In principle, the main function of trademarks, avoidance of confusion, is likely ensured by the fact that in an arm's length transaction, each contracting party would affirmatively seek not to have the goodwill of its mark diverted to the other party. ${ }^{39}$ As long as the agreement does not seek to apportion markets it would also be unobjectionable from a competition standpoint. Still, the concern remains that such agreements, which are usually not captured by the trademark offices or other public records, might undermine the public notice function of trademark law, which requires economic operators to inform the public with 'clarity and precision' of the nature of the protected subject matter. ${ }^{40}$

Nonetheless, it appears that the general axiom that shared use of a trademark is unacceptable is undergoing modification, and the notion that coexistence of marks in the market does not necessarily cause harm is gaining traction. Scholars and courts would have to focus on defining the circumstances in which coexistence can be tolerated and those in which it cannot, and articulating measures apt to provide appropriate and sufficient means to rule out serious risk to the public. ${ }^{41}$

\footnotetext{
38 See Annette Kur, Chapter 4.

39 See ibid.

40 See ibid.

41 See ibid.
} 


\section{CREATION AND SHARED KNOWLEDGE}

Other models of knowledge sharing exist which, even though not collaborative, lead to accelerated innovation. This is well illustrated by the case of the fashion industry. Deviating from the classical exclusionary IP model, the fashion industry operates on a broadly shared knowledge basis, mostly without contractual restrictions. A possible explanation for the success of this model is sought in the effect of the expressive dimensions of design, self-expression and social expression, which, in the presence of massive knowledge spillover within the industry, accelerate consumption and increase demand for products. ${ }^{42}$ This leads to the hypothesis that product demand, fuelled by the combined effect of disclosure of the product's IP content and the expressive dimensions of design, is capable of providing sufficient incentive to create, independent of the incentive provided by IP laws.

\section{CONCLUSION}

These and other models of knowledge sharing will be dealt with in detail in the various chapters of this book. However, within the general trend towards increasingly open innovation environments, a wide variety of other models exist. Furthermore, as new technologies develop, as new pathways for dissemination knowledge emerge and new players appear on the innovation scene, the ways in which knowledge can be shared will evolve as well. We are merely starting out on the path of shared knowledge. ${ }^{43}$ 